\title{
INMEDIACIÓN A LA CULTURA DE LA PREVENCIÓN Y LA COMUNICACIÓN EN CRISIS, A TRAVÉS DE SUS RESPONSABLES. ESTUDIO DE CASO EN SAN LUIS POTOSÍ, MÉXICO
}

\author{
Ramírez Tristán, Claudia \\ Gabino Campos, María A. \\ Universidad Autónoma de San Luis Potosí \\ Martínez Solana, María Yolanda \\ Universidad Complutense de Madrid \\ mymartinez@ccinf.ucm.es
}

Material original autorizado para su primera publicación en la revista académica REDMARKA. Revista Digital de Marketing Aplicado.

https://doi.org/10.17979/redma.2013.01.011.4803

Recibido: 15 Octubre 2013

Aceptado 3 Diciembre 2013

\section{Resumen}

Pensar en crisis no es un imaginario deseable para ninguna persona, porque la crisis supone inestabilidad y cambio, lo cual crea prioritariamente incertidumbre. Incertidumbre de la cual el ser humano se aleja porque la vida estable sin sobresaltos es lo deseable, pero en las últimas décadas la globalización y la tecnologización están provocando que el cambio se incorpore a la vida como parte de ella y no sea una excepción sino una realidad.

Por ello se hace necesario conocer la concepción de la comunicación en general, la cultura de prevención, y la comunicación en crisis en particular, y para ello se 
toman los agentes responsables de instancias gubernamentales y educativas de San Luis Potosí, México, para conocer si existen o no una cultura de prevención. Para ello, se utilizaron entrevistas focalizadas en busca de un alcance exploratorio. Los primeros resultados aportan la debilidad de la cultura de prevención y comunicación en crisis en las instancias estudiadas.

Palabras claves: Crisis informativa, Comunicación en crisis, Cultura de la prevención.

\section{Abstract}

Think of crisis is not desirable for anyone imagined, because the crisis is instability and change, which creates uncertainty priority. Uncertainty which humans away because the smooth stable life is desirable, but in recent decades globalization and technological transformation are causing the change is incorporated as part of life and it is not an exception.

Therefore it is necessary to know the concept of communication in general, the culture of prevention, and crisis communication in particular and the agents responsible for this government and educational consulting San Luis Potosi, Mexico are taken, for if exist or not a culture of prevention. To do this, focused on looking for a powerful exploratory interviews were used. The first results provide weak culture of prevention and crisis communication in the studied instances.

Keywords: Information Crisis, Crisis Communication, Prevention Culture.

\section{Introducción}

En las últimas décadas hemos tenido innumerables eventos que han causado grandes tragedias. El descarrilamiento del tren en Santiago de Compostela en 2013, los atentados en Madrid en marzo de 2004, el Tsunami en Indonesia en el mismo año, el Huracán Katrina en agosto de 2005, el terremoto en Haití en el año 
2010, el maremoto de Japón en el 2011 o el terremoto en México de 1985 son sucesos que trascendieron mediáticamente y ocuparon durante varias semanas la agenda setting mundial, aunque el ataque a las Torres Gemelas en septiembre de 2001 es quizás el caso más emblemático de los últimos tiempos en la gestión de comunicación en momentos de crisis ya que aconteció en unos los países más poderosos del mundo y mayor visibilidad mediática. Asimismo, los gobiernos de todos estos países tuvieron inmediatamente que poner en marcha un gabinete de crisis donde el manejo de la comunicación en este momento tuvo suma relevancia. A la par de estas situaciones existen las crisis monetarias, ambientales, de salud, de seguridad, entre otras con sus diferencias y particulares en cualquier parte del mundo, pero la mayoría de las culturas no han estado preparadas para enfrentar estas crisis debido a que éstas acontecen repentinamente y los gobiernos no constituyen regularmente células de manejo de crisis de manera previa y con ello, el caos informativo del primer momento puede derivar en un problema de comunicación y en alarma social por la desinformación o por sobresaturación.

Estos hechos evidenciaron la importancia y la necesidad de establecer estrategias en momentos de crisis, pero también han facilitado datos empíricos para establecer parámetros de actuación, ya que se evidencian aspectos comunes a cualquier crisis informativa como sustenta la investigadora Maria Yolanda Martínez Solana:

- Negación inicial del problema.

- Infravaloración del problema, cuando la realidad lo impone.

- Desconcierto e inacción por parte de las autoridades, cuando no desafortunadas declaraciones y actuaciones.

- Como consecuencia, desconfianza y quejas por parte de los afectados.

- Repercusiones en los medios como información de patrón agudo. (Martínez Solana, 2003, p.149) 
Es evidente que en una situación de crisis, "la noticia no deja de existir, aunque la fuente la niegue; simplemente, podrá salir más tarde y con otra base documental (quizás, otra fuente menos fiable y más interesada) y se habrá perdido una ocasión de que la versión inicialmente solicitada por el periodista salga a la luz pública." (Martínez Solana, 2003, p.150)

\section{Crisis}

La actualidad se asume como época de cambios. No sólo porque vivimos sumisos en una temporalidad de la inmediatez sino porque el cambio es parte de la cotidianidad de la vida, nada parece o es estable. $Y$ estos cambios provocan crisis porque ésta es un cambio repentino entre dos situaciones, cambios que ponen en peligro la imagen y el equilibrio natural de una organización porque entre las dos situaciones (la situación anterior y la situación posterior a la crisis) se produce un acontecimiento súbito (inesperado o extraordinario) frente al cual una organización tiene que reaccionar comprometiendo su imagen y su equilibrio interno (como organización) y externo (como institución) ante sus públicos.

Steve Albrecht (1996) considera las crisis "como eventos específicos que pueden romper el equilibrio de una organización, dependiendo del tamaño de la compañía, del número de empleados que ésta tenga, del producto y de sus servicios."

Crisis es sinónimo de escasez, de carencias, de conflicto, de tensión, urgencia, desestabilización y unicidad, sucede por el hecho de no conocer nuestra propia identidad y de no haber dedicado el esfuerzo necesario en prepararnos para afrontar las dificultades. El diccionario de la Real Academia de la Lengua Española (RAE) entiende por crisis: "a una situación de un asunto o proceso cuando está en duda la continuación, modificación o cese." Por consiguiente, la crisis es una situación o proceso que sufre un cambio repentino, en el cual se da una ruptura del equilibrio que puede poner en duda la continuación o modificación del mismo.

Según Martínez Solana (2003, p.145) la crisis en general consta de cuatro fases: Preliminar, Aguda, Crónica y de Recuperación o fin de la crisis. Mientras los efectos de dichas crisis "se traducen en: Nerviosismo y desorganización, 
contradicciones entre las fuentes y situación de desbordamiento ante el exceso de demanda informativa." (Martínez Solana, 2003, p.146)

Para Martínez, la inexistencia de información provoca inquietud por lo cual, "el reto implica impedir que esa sensación de aturdimiento informativo evolucione hacia la percepción de alarma. Prolongar el tiempo que transcurre entre las primeras fases o el inicio de persecución de la noticia por los medios informativos y el reconocimiento por parte de las organizaciones implicadas contribuye a acentuar la crisis." (2003)

\section{Teoría de la ampliación de riesgo}

La teoría de ampliación de riesgo de Masuda y Garvin (2006) se plantea como sustento teórico en este estudio ya que plantea como esencial el diálogo con el público y explica el impacto potencial de un evento riesgoso. En otras palabras, según el tipo y manera como se plasme la información puede influir en la opinión y en la concepción de riesgo que adopte la sociedad.

Tres décadas de intensa investigación tanto teórica como metodológica rodean a la teoría de amplificación de riesgos. En los últimos años, el rol del contexto y la cultura han sido incorporados a esta teoría (Masuda \& Garvin, 2006; Rosa, 1998; Short, 1987; Wilkinson, 2001; Wynne, 1992). Masuda y Garvin (2006) demostrando que el espacio y las cosmovisiones culturales llevan a la amplificación del riesgo para las personas que viven en la comunidad en peligro, mientras el riego se atenúa para las que no viven en sus cercanías.

La teoría de amplificación de riesgos ha sido sumamente utilizada en estudios cualitativos (Pidgeon, Kasperson \& Slovic, 2003), así como en algunos estudios correlacionales a través de cuestionarios (Frewer, Miles, \& Marsh, 2002; Scherer \& Cho, 2003). En particular, Frewer y sus colegas (2002) encontraron que la teoría de amplificación de riesgos sirve para comenzar el diálogo con el público y explicar el impacto potencial de un evento riesgoso. 
Esta teoría se utilizó para el análisis de accidentes como el sucedido en la mina de carbón "Pasta de Conchos" en el año 2006 en Coahuila (México), debido a que "la amplificación de riesgo" es la interpretación subjetiva de un mensaje dado que las personas exageran o minimizan el riesgo al que están expuestos, por lo cual esta percepción se vuelve un proceso social en el cual interviene la cultura y el contexto; es por ello que ésta es la teoría más adecuada para utilizar debido a que también podemos considerar que la crisis es un proceso cultural, ya que cotidianamente escuchamos frases como: "el país está en crisis", "siempre hemos vivido en crisis", entre otras, y es así como la gente establece en su imaginario colectivo la crisis como algo natural y por ello no existe una cultura de la prevención.

\section{Comunicación en crisis}

En nuestros días la comunicación de crisis, que consiste básicamente en un planteamiento de cómo abordar situaciones riesgosas, difíciles o críticas y ha tomado importancia debido a los sucesos que ocurren en el mundo, a lo largo de nuestra vida estamos rodeados de riesgos, y es por es que tenemos la necesidad de identificarlos, controlarlos y en lo posible tratar de evitarlos. (Tejeda y PérezFloriano, 2011, pp. 71-99)

Sandman (2003) define la comunicación en crisis como un conjunto de capacidades y conocimientos para transmitir a la sociedad una información adecuada sobre una situación riesgosa, reconociendo la incertidumbre que esta puede generar y sin intentar eliminar por completo los temores. Para ello se requiere la planificación, identificación de lenguajes, gestión de percepciones y la búsqueda de los puntos de equilibrio.

Por lo tanto la comunicación de crisis debiera ser, en esta lógica un instrumento que permita dotar de certidumbre a la sociedad, gobierno e instituciones ante situaciones de amenaza; ya que en una crisis se espera que los líderes reduzcan la incertidumbre y proporcionen una narración autorizada acerca de qué está pasando, por qué está sucediendo y qué es necesario hacer (Martínez Solana, 
2003). Sin embargo esto no es puesto en práctica ya que el silencio suele ser el primer elemento presente durante una crisis, es ahí donde la información se tergiversa y surgen los rumores, los cuáles puede afectar la imagen, la comunicación interna y externa de cualquier sector, además de que la crisis se convierte en un conflicto simbólico sobre el significado social acerca del dominio de un asunto. Afectan valores e intereses fundamentales de las comunidades y el precio de las elecciones "buenas" o "malas" es elevado social, política y económicamente, y en términos humanos.

Es por ello que la gestión de una buena comunicación interna; a la cual Carlos Fernández Collado la define como: "El conjunto de actividades efectuadas por cualquier organización para la creación y mantenimiento de buenas relaciones con y entre sus miembros, a través del uso de diferentes medios de comunicación que los mantenga informados, integrados y motivados para contribuir con su trabajo al logro de los objetivos organizacionales." (2002, p.368)

Esta revisión documental teórico-conceptual nos permite plantearnos la premisa de investigación donde se considera que las empresas, organizaciones o instituciones en San Luis Potosí, México, no tienen una cultura de prevención y menos aún protocolos adecuados para la comunicación en crisis.

\section{Aproximación al trabajo de campo}

El paradigma desde el cual se plantea este trabajo es humanista-interpretativo porque éste se centra en las personas e intenta describir e interpretar fenómenos y se interesa por el estudio de los significados e intenciones de las conductas humanas, a través de este es posible comprender la profundidad del significado de los fenómenos.

Asimismo se plantea un alcance descriptivo ya que se busca a través de la medición de uno o más datos que se encuentren crear una imagen exacta de la realidad a través de sus posibles actores.

Desde el enfoque cualitativo, se aborda el objeto de estudio con entrevistas focalizadas y la interacción directa con los sujetos implicados y responsables, para 
alcanzar el objetivo de conocer el concepto de la comunicación dentro de las áreas de gubernamentales y de educativas responsables de las áreas de crisis en el Estado de San Luis Potosí, México.

Los sujetos elegidos son:

- El Centro de Inteligencia de la Secretaría de Seguridad Pública del Estado de San Luis Potosí: Fue elegida debido a que es aquí de donde salen las medidas que debe de tomar la población ante una situación de crisis por inseguridad.

- El Departamento de Protección Civil Universitario de la UASLP: El motivo por el cual fue elegido este departamento es para hacer una comparación en materia de cómo son aplicados los protocolos dentro de una institución educativa como lo es la Universidad Autónoma de San Luis Potosí.

Para esta selección se tomó como criterio de inclusión, los encargados de los departamentos de comunicación/ creación de protocolos de las instituciones seleccionadas. Mientras se excluyeron, personas que aun trabajando en las instituciones no estén directamente relacionadas con la creación y/o difusión de los protocolos.

Las entrevistas focalizadas se elaboraron partiendo de las siguientes categorías de análisis: Comunicación en general, comunicación organizacional, comunicación en crisis, inseguridad y protocolos.

Dichas categorías de análisis se desglosaron en las siguientes variables:

\begin{tabular}{|l|c|}
\hline \multicolumn{1}{|c|}{ CATEGORÍAS } & VARIABLES \\
\hline Comunicación & $\begin{array}{c}\text { Concepto } \\
\text { La relación } \\
\text { comunicación/empresa }\end{array}$ \\
\hline Comunicación Organizacional & $\begin{array}{c}\text { Departamento de } \\
\text { comunicación } \\
\text { Imagen institucional }\end{array}$ \\
\hline Comunicación en crisis & $\begin{array}{c}\text { Concepto } \\
\text { Solución de crisis }\end{array}$ \\
\hline
\end{tabular}




\begin{tabular}{|l|c|}
\hline Inseguridad & $\begin{array}{c}\text { Percepción } \\
\text { Manejo }\end{array}$ \\
\hline Protocolos & Concepto \\
& Manejo \\
& Desarrollo \\
\hline
\end{tabular}

Fuente propia

Las entrevistas fueron llevadas a cabo por vía electrónica durante los días del 15 al 22 de abril del año 2013.

\section{Discusión y conclusiones}

La gestión de la comunicación en ambas entidades está a cargo del departamento de comunicación. Además, la consideran como esencial para lograr los objetivos planteados y mejorar la relación tanto laboral como con la población en general. A pesar que tienen una gran relevancia en ambas instituciones, el desempeño de la comunicación se cumple de manera satisfactoria, pero solo de manera interna en las dos instituciones.

Dentro de las actividades de los departamentos están la difusión de los protocolos de seguridad y cualquier actividad realizada, así como mantener buenas relaciones con los medios de comunicación.

Cuando se insta a la crisis, el concepto está mejor manejado por el Departamento de Protección Civil Universitaria, ya que el Centro de Inteligencia sólo se refiere a ello como "un estado de alerta" y se queda en esa conceptualización, mientras que Protección Civil lo construye como una situación que pese a sus esfuerzos se salió de control y por consecuencia puede generar terribles daños.

La creación de los protocolos en ambas dependencias está estructurada para saber que hacer antes, durante y después de una situación de riesgo, lo cual en ambas instancias existe una preocupación por una cultura de la prevención, sin embargo la difusión de éstos es mínima, con lo cual no llega a la gran parte de la población.

Debido a que utilizan la conferencia de prensa como su medio más fuerte de difusión, y se olvidan de la creación de carteles, manejo en redes sociales, en 
televisión, folletos, páginas web informativas sobre los protocolos, entre otros, por lo cual no hay una correcta difusión y el esfuerzo por crear una Cultura de la Prevención es sesgado porque no hay una divulgación masiva.

La teoría de ampliación de riesgos funciona en este caso, ya que retomando la idea principal: "según el tipo y manera como se plasme la información puede influir en la opinión y en la concepción de riesgo que adopte la sociedad", con lo cual al tener deficiencia en la divulgación de protocolos la incertidumbre de la población con respecto a cualquier situación es evidente que será elevada ya que desconocen cual serán los pasos que se tomarán.

Con respecto a la premisa de partida podemos confirmar que no existe una cultura de prevención y los riesgos de un desastre comunicacional en una situación de crisis es evidente.

\section{Bibliografía}

Albrecht, S. (1996). Comunicación en programas de crisis. En Jaime Fita (1999) España: Gestiòn 2000.

Andrade, H. (1996) La comunicación positiva y el entorno organizacional: El papel de la cultura y la comunicación en las crisis organizacionales. Razón y Palabra, 4, 1. Recuperado de http://www.razonypalabra.org.mx/anteriores/n4/andrade.html

Farré Coma, J. (2005). Comunicación de riesgo y espirales del miedo.

Comunicación y sociedad, (3), 95-119.

Fernández Collado, C. (2002). La comunicación en las organizaciones.

México: Trillas.

López, Nelly e Irma Sandoval. (2006). Métodos y técnicas de investigación cuantitativa y cualitativa. Sistema de Universidad Virtual, Universidad de Guadalajara.

Martínez Solana, Yolanda. (2003). La Comunicación Institucional. Análisis de sus problemas y soluciones. Fragua 
Masuda y Garvin (2006). Teoría: Amplificación Social del Riesgo. Recuperado de http://www.researchgate.net/publication/49613583_La_amplificacin_social_del_rie sgo_evidencias_del_accidente_en_la_mina_Pasta_de_Conchos Pérez, J. (1996). La comunicación positiva y el entorno organizacional: Comunicación en caso de crisis; un juego de percepciones, no de realidades. Razòn $y$ Palabra, 4, $1 . \quad$ Recuperado de http://www.razonypalabra.org.mx/anteriores/n4/ferraez.html Sandman, PM. (2003). Bioterrorism risk communication policy. J Health Commun 2003; 8 (suppl 1), 146-7.

Tejeda, N. y Pérez-Floriano, L. (2011). La amplificación social del riesgo: evidencias del accidente en la mina Pasta de Conchos. Comunicación y Sociedad, núm. 15, pp. 71-99. 